\title{
ANÁLISE SINÓTICA DO MÊS DE ABRIL DE 2018 NA REGIÃO SUL DO BRASIL: EPISÓDIO DE CALOR EXTREMO
}

\author{
JACONDINO, William Duarte - williamjacondino@hotmail.com \\ Programa de Pós-Graduação em Meteorologia - Universidade Federal de Pelotas \\ / UFPEL
}

NASCIMENTO, Ana Lucia da Silva - analuciasne@gmail.com

Programa de Pós-Graduação em Meteorologia - Universidade Federal de Pelotas / UFPEL

NUNES, André Becker - beckernunes@gmail.com

Programa de Pós-Graduação em Meteorologia - Universidade Federal de Pelotas / UFPEL

CONRADO, Humberto - hconradohc1@gmail.com Universidade Federal de Pelotas / UFPEL

\begin{abstract}
RESUMO: O mês de abril de 2018 foi noticiado o terceiro mês de abril mais quente da história desde que os registros globais de temperatura começaram em várias regiões dos Hemisférios Norte e Sul segundo órgãos oficiais nacionais e internacionais de meteorologia. O presente estudo tem como objetivo analisar as características atmosféricas de grande escala que causaram episódios prolongados de calor durante o mês em questão na região sul do Brasil. Os episódios de calor foram identificados com base nas temperaturas máximas e mínimas médias mensais que superaram o percentil 90 da série climatológica mensal de abril em 21 estações do INMET distribuídas na região de estudo. Para o estudo sinótico foram utilizados dados mensais de reanálises do MERRA-2 entre abril/1981 a abril/2018. Os resultados indicam que as altas temperaturas que predominaram durante o abril de 2018 na região de estudo estiveram associadas a uma configuração de bloqueio que se estabeleceu em decorrência da justaposição simultânea de uma formação em nível superior composta por uma crista estacionária centrada sobre a América do Sul com um anticiclone atípico persistente em baixos níveis atuando sobre o Oceano Atlântico no sul do País. O transporte efetivo de umidade específica nos baixos níveis realizado pelo Anticiclone Subtropical do Atlântico Sul foi um fator importante para a manutenção das altas temperaturas, especialmente durante 0 período noturno uma vez que o vapor d'água em excesso nesta parte da camada atmosférica retém mais radiação de onda longa e manteve as temperaturas mínimas mais elevadas.
\end{abstract}

Palavras-chave: Bloqueio atmosférico, Ondas de calor, Sistemas frontais

SYNOTIC ANALYSIS OF APRIL 2018 IN THE SOUTH REGION OF BRAZIL: AN EXTREME HEAT EPISODE

ABSTRACT: April 2018 was reported the third warmest month in April since global temperature records began in various regions of the Northern and Southern Hemisphere according to official national and international meteorological institutions. The present study aims to analyze the large-scale atmospheric features that caused prolonged heat episodes during the month in question in the southern region of Brazil. The heat episodes were identified based on the maximum and minimum monthly average temperatures that surpassed the 90th percentile of the monthly climatological series of April in 21 meteorological INMET stations distributed in the south of Brazil. For the synoptic study, monthly MERRA-2 reanalysis data were used between April / 1981 and April / 2018. The results indicate that the higher temperatures that prevailed during April 2018 in the study region were associated with a blocking configuration that was established due to 
the simultaneous juxtaposition of a upper level system composed of a stationary ridge centered on South America with a persistent atypical anticyclone at low levels on the Atlantic Ocean in the south of the country. The effective transport of specific humidity at low levels carried out by South Atlantic subtropical high was an important factor in maintaining high temperatures, especially at night since excess of water vapor at this part of the atmospheric layer retains more long-wave radiation and maintained the highest minimum temperatures.

Keywords: Atmospheric blocking, Heat waves, Frontal systems

\section{INTRODUÇÃO}

A região sul do Brasil (RSB) compreendida pelos estados do Rio Grande do Sul (RS), Santa Catarina (SC) e Paraná (PR) situa-se no cinturão de latitudes subtropicais, cujo clima apresenta as estações do ano bem definidas (CAVALCANTI et al., 2009a). O outono na região transcorre entre os meses de abril e junho, sendo caracterizado por um aumento gradual ao longo da estação na frequência, intensidade e duração das invasões de massas frias. Por ser no mês de abril o início da transição do verão para o outono, as temperaturas são tipicamente quentes e de verão no início, mas no decorrer do mês, com a passagem sistemas frontais com oscilações de temperatura mais acentuada, dias com temperaturas mais baixas vão marcando maior presença. Em decorrência da variabilidade, o regime de queda da temperatura ao longo do mês pode ser mais ou menos acentuado conforme o ano, o que resulta em algumas situações um mês de abril com predominância de dias mais quentes e pouca oscilação na temperatura e em outros meses com regimes de temperatura mais típico do meio do outono (CAVALCANTI e KOUSKY, 2009b).

Ao longo do ano, distintos sistemas meteorológicos influenciam as condições do tempo na RSB, determinando as temperaturas, precipitações, nebulosidade e condições de céu claro. Os sistemas frontais são o principal sistema a provocar oscilação das temperaturas diárias por estarem associados ao deslocamento de massas de ar quente e fria (KOUSKY, 1979; OLIVEIRA, 1986; RODRIGUES et al., 2004; ANDRADE, 2007, REBOITA et al. 2010). Quanto a sistemas mais associados a precipitações, podem-se destacar também os ciclones e frentes que se desenvolvem na região devido à presença de vórtices ciclônicos ou cavados em altos níveis sobre a costa oeste da América do Sul vindos do Pacífico (MIKY FUNATSU et al., 2004, IWABE e DA ROCHA, 2009), e também devido a condições frontogenéticas e/ou ciclogenéticas originadas entre - Sul do Paraguai, Uruguai e RSB (SATYAMURTY e MATTOS, 1989; REBOITA, 2008; REBOITA et al., 2009); Complexos Convectivos de Mesoescala (CCMs) (FIGUEIREDO e SCOLAR, 1996; SALIO et al., 2007); sistemas ciclônicos em níveis médios conhecidos como vírgula invertida (BONATTI e RAO, 1987; HALLAK, 2000) e, por fim, os bloqueios atmosféricos (MARQUES e RAO, 1999; NASCIMENTO e AMBRIZZI, 2002). Grande parte do regime pluviométrico na RSB se deve a atuação dos sistemas mencionados acima, com destaque para os sistemas frontais que ocorrem regularmente ao longo do ano, porém com uma maior frequência entre os meses de maio e setembro, diminuindo entre os meses de outubro e abril (OLIVEIRA, 1986; LEMOS e CALBETE, 1996; JUSTI DA SILVA E SILVA DIAS, 2002; CAVALCANTI e KOUSKY, 2009b).

O mês de abril de 2018 foi um dos meses de abril mais quentes dos últimos anos segundos dados observados em diversas estações meteorológicas do Instituto Nacional de Meteorologia (INMET, 2018a). Na RSB, em especial o estado do RS, vários municípios apresentaram temperaturas máximas e 
mínimas do ar superiores as suas respectivas normais climatológicas por vários dias consecutivos ao longo deste mês. Segundo a National Oceanic and Atmospheric Administration (NOAA, 2018) as temperaturas do mês de abril de 2018 também foram as mais quentes dos últimos tempos na vizinha Argentina e a superar recordes históricos de temperatura em diversas regiões do Hemisfério Norte, sendo que em algumas localidades foi classificado como o terceiro abril mais quente da história desde que os registros de temperatura começaram. A Figura 1 destaca as regiões que apresentaram os registros mais relevantes durante o mês em questão segundo dados da NOAA (2018), onde os pontos circulares destacados em vermelho e azul apresenta as regiões em que foram observados recordes de temperaturas mais quentes e mais frias, respectivamente, em relação a série histórica (climatológica) de referência de cada localidade.

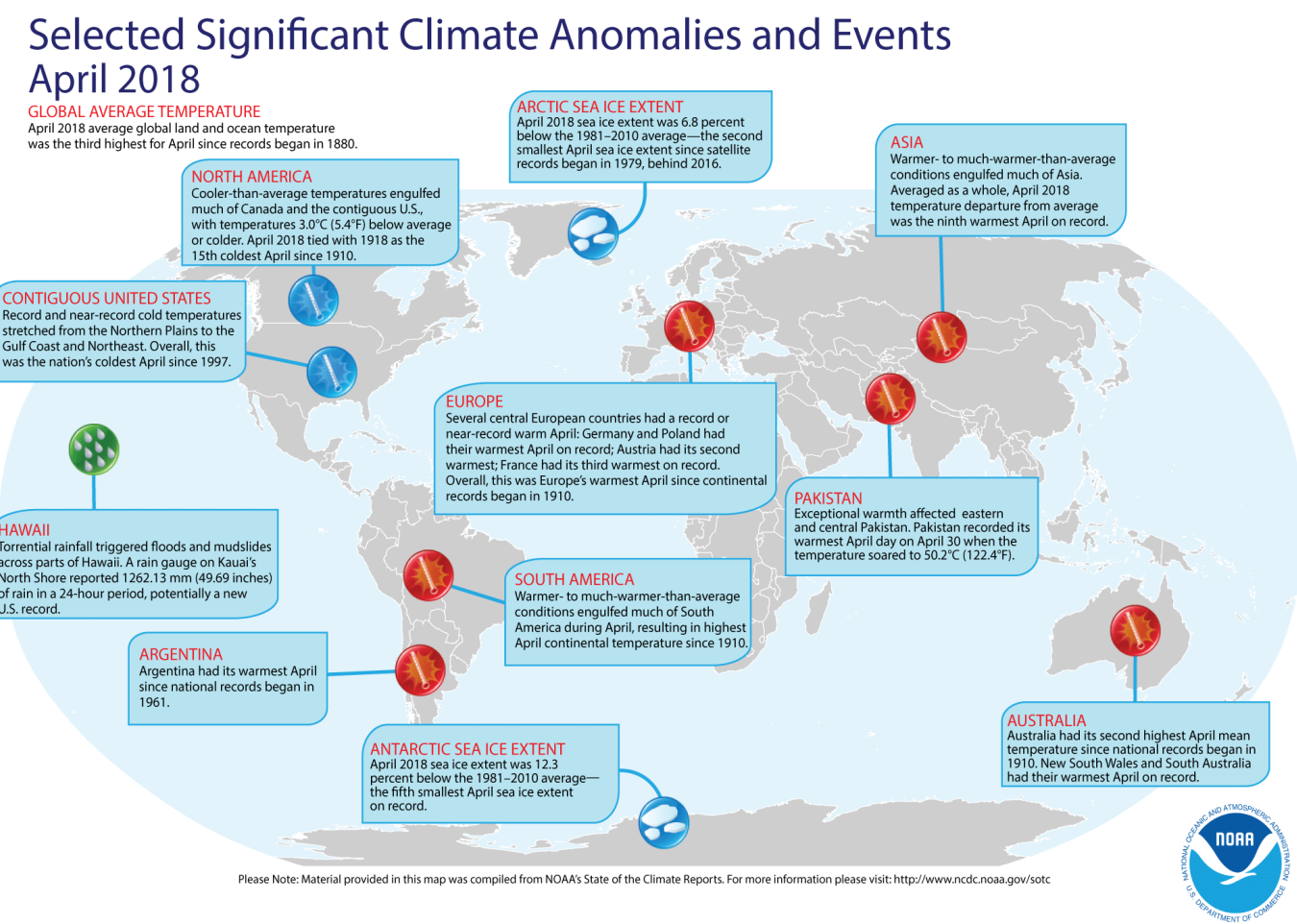

Figura 1 - Mapa do mundo destacando eventos climáticos notáveis que ocorreram durante o mês de abril-2018. Fonte: https://www.noaa.gov/news/april-2018-was-3rdwarmest-on-record-for-globe (2018).

Estudos caracterizando a climatologia de sistemas frontais na região sul como o de Lemos e Calbete (1996) e Jesus et al. 2016 verificaram que em média entre quatro a seis sistemas frontais atuam por mês nesta região. Entretanto, no mês de abril de 2018 apenas dois sistemas frontais conseguiram avançar sobre o sul do país (CPTEC/INPE, 2018). A persistência de temperaturas elevadas atuando sobre o estado do RS durante o abril de 2018 pode estar associada com esta baixa frequência de sistemas frontais atuando na região, haja vista que a precipitação acompanhada destes sistemas tende a reduzir a temperatura da atmosfera na região em que atua. Em situações de baixa frequência de propagação de sistemas frontais, a incursão de massas frias oriundas de latitudes mais ao sul são escassas, deixando a região sob condições 
de tempo quente e seco. Segundo Satyamurty et al. (1998) geralmente estas situações estão associadas a ação de sistemas de bloqueio em níveis médios da atmosfera sobre a América do Sul (AS), que ocasionam o desvio da circulação atmosférica de modo a interromper o deslocamento dos sistemas de precipitação para a região. Ademais, a redução da precipitação pode também explicar a menor amplitude térmica no mês, ao atuar para manter as temperaturas mais altas por um período de tempo maior como mostraram os registros do mês de abril de 2018 (INMET, 2018a). O processo de precipitação é um dos principais mecanismos reguladores da temperatura do ar, uma vez que este tende a acarretar a incursão de ar com baixa temperatura potencial equivalente nos níveis mais baixos da atmosfera (MOTA e NOBRE, 2006), o que causa a diminuição da temperatura em tal região.

Eventos climáticos extremos tais como a incidência de ondas de calor (OC) são esperados em períodos que apresentam dias consecutivos de calor intenso (MARENGO, 2008; GEIRINHAS et al. 2018). Os eventos associados a ocorrência de OC em latitudes médias podem ser melhor contextualizados ao considerar-se a dinâmica da grande escala que favorece os processos termodinâmicos e as interações oceano-atmosfera (LAU e NATH, 2012; LEE e GROTJAHN, 2016). A gênese das OC é geralmente associada ao estabelecimento de um padrão de circulação atmosférica anticiclônica de grande escala persistente (BLACK et al., 2004; DOLE et al., 2011), caracterizadas por altas pressões principalmente em níveis médios, que induzem movimento vertical descendente do ar (subsidência) levando a condições de céu claro, atmosfera seca, ventos fracos em superfície, advecções de massas de ar quente e períodos prolongados com temperaturas mais altas do que o habitual (XOPLAKI et al., 2003; MEEHL e TEBALDI, 2004; GEIRINHAS et al., 2017). Quando essas altas pressões são semi-estacionárias ou estacionárias, são frequentemente referidos como "bloqueios", pois alteram a trajetória padrão (climatológica) da corrente de jato e impedem o avanço dos sistemas sinóticos de latitudes médias (BARNES et al., 2012; PFAHL et al., 2015). As condições de tempo decorrentes dos padrões de bloqueio em níveis médios e altos propicia uma transferência de energia radiativa muito eficiente, caracterizada por valores altos de radiação solar incidente na superfície, que está associada a condições meteorológicas de estiagem (representada por anomalias negativas de precipitação e umidade relativa) (SOUSA et al., 2017; GEIRINHAS et al., 2017). No Brasil, Geirinhas et al. 2017 observou que os episódios de OC ocorridos na região sul durante o verão se desenvolvem mais facilmente quando as condições meteorológicas radiativas e de estiagem descritas acima ocorrem em associação com uma migração do Anticiclone Subtropical do Atlântico Sul (ASAS) para oeste. O autor verificou ainda que essa migração para oeste do ASAS ocorre quando o padrão de fluxo em $500 \mathrm{hPa}$ que guia as ondas baroclínicas (associadas a frentes frias na superfície) desloca-se para latitudes mais altas como um fator importante para que o ASAS se situe mais próximo do continente. Esse deslocamento para sudoeste do ASAS dificulta a passagem de sistemas frontais que geralmente afetam as regiões sul, sudeste e centro-oeste do Brasil, proporcionando um ambiente com condições meteorológicas favoráveis de temperatura para o desenvolvimento de OC devido aos processos de subsidência que promovem a diminuição da umidade na atmosfera, redução da nebulosidade (prevalecendo condições de céu claro) e aos altos níveis de incidência de radiação solar na superfície (SOUSA et al., 2017). 
Apesar de haver diferentes trabalhos que documentam a ocorrência de episódios extremos de calor na América do Sul (BITENCOURT et al., 2016; CECCHERINI et al., 2016; CERNE \& VERA, 2011; GEIRINHAS et al., 2017; GEIRINHAS et al., 2018; HANNART et al., 2015; RENOM et al., 2011; RUSTICUCCI, 2012; RUSTICUCCI et al., 2016, 2017; BEZERRA, 2016; BEZERRA e NUNES, 2017), o número de estudos explorando o ambiente sinótico associado a esses eventos ainda é escasso quando se trata de estações de transição como o outono. Neste contexto, o presente trabalho tem como objetivo verificar o ambiente atmosférico de grande escala que propiciou a ocorrência dos episódios de calor extremo na RSB no mês de abril-2018 a partir de uma análise sinótica.

\section{MATERIAL E MÉTODOS}

Para a realização do presente estudo, recolheram-se valores mensais de temperatura máxima e mínima do ar relativos a 21 estações meteorológicas (Tabela 1) distintas da RSB entre o período 1961-2018 pertencentes ao INMET.

Tabela 1 - Caracterização geográfica das estações meteorológicas utilizadas.

\begin{tabular}{cccc}
\hline Estação & Latitude (S) & Longitude (W) & Altitude (m) \\
\hline Porto Alegre - RS & $30,01^{\circ}$ & $51,21^{\circ}$ & 46,97 \\
Bagé - RS & $31,33^{\circ}$ & $54,1^{\circ}$ & 242,31 \\
Bom Jesus - RS & $28,66^{\circ}$ & $50,43^{\circ}$ & 1047,5 \\
Caxias do Sul - RS & $29,19^{\circ}$ & $51,18^{\circ}$ & 751 \\
Cruz Alta - RS & $28,63^{\circ}$ & $53,6^{\circ}$ & 472,5 \\
Encruzilhada do Sul - RS & $30,53^{\circ}$ & $52,51^{\circ}$ & 427,75 \\
Passo Fundo - RS & $28,21^{\circ}$ & $52,4^{\circ}$ & 684,05 \\
Pelotas - RS & $31,78^{\circ}$ & $52,41^{\circ}$ & 13 \\
Santa Maria - RS & $29,7^{\circ}$ & $53,7^{\circ}$ & 95 \\
São Luiz Gonzaga - RS & $28,4^{\circ}$ & $55,01^{\circ}$ & 245,11 \\
Torres - RS & $29,35^{\circ}$ & $49,73^{\circ}$ & 4,66 \\
Uruguaiana - RS & $29,75^{\circ}$ & $57,08^{\circ}$ & 62,31 \\
Florianópolis - SC & $27,6^{\circ}$ & $48,62^{\circ}$ & 1,84 \\
Lages - SC & $27,8^{\circ}$ & $50,33^{\circ}$ & 953 \\
Castro - PR & $24,78^{\circ}$ & $50^{\circ}$ & 1008,8 \\
Curitiba - PR & $25,43^{\circ}$ & $49,26^{\circ}$ & 923,5 \\
Irati - PR & $25,5^{\circ}$ & $50,63^{\circ}$ & 836,95 \\
Ivaí - PR & $25^{\circ}$ & $50,85^{\circ}$ & 808 \\
Londrina - PR & $23,31^{\circ}$ & $51,13^{\circ}$ & 566 \\
Maringá - PR & $23,4^{\circ}$ & $51,91^{\circ}$ & 542 \\
Paranaguá - PR & $25,53^{\circ}$ & $48,51^{\circ}$ & 4,5 \\
\hline
\end{tabular}

A escolha das estações foi feita respeitando o critério de optar pelas estações com o menor número de dados em falta. 


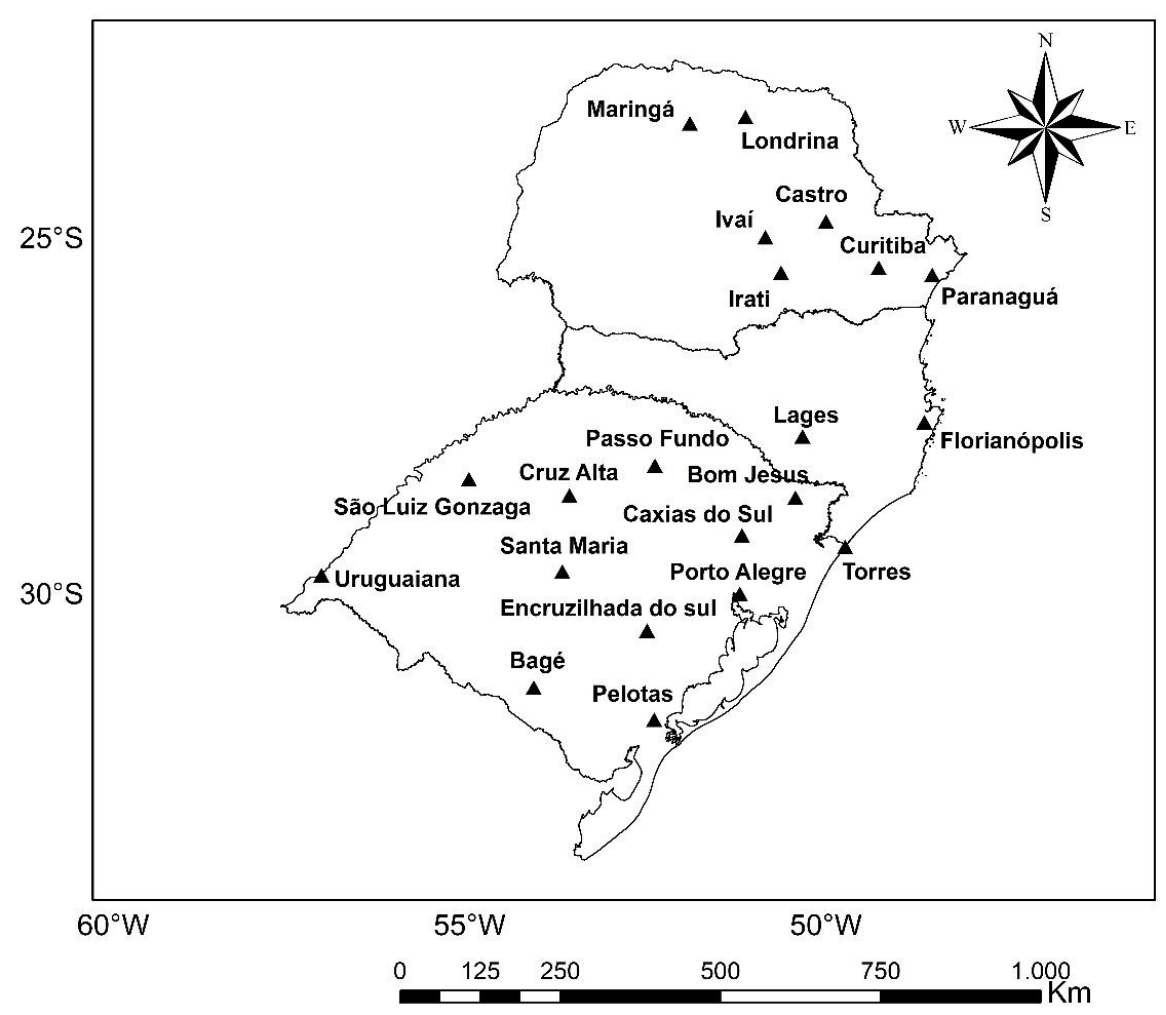

Figura 2 - Representação da localização das estações meteorológicas (triângulos em preto) na RSB utilizadas no trabalho

A identificação de eventos extremos de calor como as OC geralmente é feita por meio de índices que utilizam na sua maioria limiares de temperatura para a identificação de OC. Assim, a OC é definida como um período de tempo relativamente longo cujas temperaturas máximas e/ou mínimas excedem um dado limiar, sendo que muitas vezes este limiar é baseado em valores de percentil de temperatura (FISCHER e SCHÄR, 2010; GEIRINHAS et al., 2017; GEIRINHAS et al., 2018; PERKINS \& ALEXANDER, 2013). Neste trabalho, a metodologia adotada para caracterizar episódios de calor extremo foi adaptada de Fischer e Schär (2010) e Geirinhas et at. (2017) para o período de um mês (abril de 2018), em que as temperaturas máximas e mínimas médias mensais devem ser superior ao valor climatológico (1961-1990) do percentil 90 (p90) para ambas variáveis do período em questão para configurarem um episódio de calor extremo.

Para a análise sinótica foram utilizados dados mensais de reanálises com resolução de $0.66^{\circ}$ de longitude e $0.5^{\circ}$ de latitude do Modern Era RetrospectiveAnalysis for Research and Applications (MERRA-2) (GELARO et al., 2017). Analisou-se os dados mensais (abril de 2018) de temperatura e umidade específica a dois metros da superfície, em 850, 500 e $250 \mathrm{hPa}$, umidade relativa em 850, 500 e $250 \mathrm{hPa}$, altura geopotencial em $500 \mathrm{hPa}$, espessura entre 500 e $1000 \mathrm{hPa}$, pressão ao nível médio do mar (PNMM), e vento em 850, 500 e 250 $\mathrm{hPa}$. Analisou-se também a diferença entre os campos gerados para o mês de abril de 2018 com os campos climatológicos (1981-2010) do mês em questão, haja vista que os dados de reanálise usados aqui compreendem o período de 1979 até o presente. 
As informações são fornecidas em pontos de grade, onde foi utilizado o software GrADS (Grid Analysis and Display System) para a devida visualização dos dados citados. O GrADS é um sistema de visualização e análise de dados em pontos de grade, trabalha com matrizes de dados binários, nas quais as variáveis podem possuir até quatro dimensões (longitude, latitude, níveis verticais e tempo) (SOUZA, 2004).

\section{RESULTADOS E DISCUSSÃO}

A tabela 2 apresenta os valores médios mensais das temperaturas máximas e mínimas do mês de abril 2018 e o percentil 90 de ambas variáveis da série climatológica (abril, 1961-1990) que são utilizadas como referência para identificar episódios de calor mensal. O aumento da temperatura máxima do mês de abril-2018 na RSB é observado a partir da comparação com o correspondente p90 (Tabela 2 e Figura 3) onde 20 das 21 estações apresentam temperaturas médias máximas superiores ao p90, destacando as maiores diferenças positivas por estado as cidades de Santa Maria, Florianópolis e Ivaí, com valores de $2.6^{\circ} \mathrm{C}, 2.8^{\circ} \mathrm{C}$ e $1.9^{\circ} \mathrm{C}$, respectivamente. A comparação das temperaturas mínimas com o respectivo p90 aponta também para um aumento significativo das temperaturas noturnas no mês de abril-2018, 17 das 21 estações com temperaturas medias mínimas superiores ao p90 da série climatológica (Figura 4), destacando as maiores diferenças positivas por estado as cidades de São Luiz Gonzaga e Pelotas no RS com valores de $2.4^{\circ} \mathrm{C}$, Lages com $0.6^{\circ} \mathrm{C}$ em SC e Maringá com $0.6^{\circ}$ no $\mathrm{PR}$, respectivamente.

Tabela 2 - Valores médios mensais das temperaturas máximas (TMax abril $2018,{ }^{\circ} \mathrm{C}$ ) e mínimas (TMax abril 2018, ${ }^{\circ} \mathrm{C}$ ) do mês de abril de 2018 e o percentil 90 das temperaturas máximas ( $\left.\mathrm{p} 90 \%-\mathrm{TMax}^{\circ}{ }^{\circ} \mathrm{C}\right)$ e mínimas mensais de abril ( $\mathrm{p} 90 \%$ TMin, $\left.{ }^{\circ} \mathrm{C}\right)$ da série climatológica (1961-1990).

\begin{tabular}{ccccc}
\hline Cidades & $\begin{array}{c}\text { p 90\% - TMax } \\
(1961-1990)\end{array}$ & $\begin{array}{c}\text { TMax } \\
\text { abril } 2018\end{array}$ & $\begin{array}{c}\text { p 90\% - TMin } \\
(1961-1990)\end{array}$ & $\begin{array}{c}\text { TMin } \\
\text { abril 2018 }\end{array}$ \\
\hline Porto Alegre - RS & 27,2 & 28,9 & 17,8 & 19,3 \\
Bagé - RS & 26,3 & 28,03 & 15,6 & 18,2 \\
Bom Jesus - RS & 22,3 & 24,4 & 12,8 & 13,2 \\
Caxias do Sul - RS & 23,4 & 25,4 & 14,6 & 16,7 \\
Cruz Alta - RS & 27,1 & 28,6 & 15,8 & 17,3 \\
Encruzilhada do Sul - RS & 24,2 & 26,7 & 15,4 & 17,48 \\
Passo Fundo - RS & 25,8 & 26,98 & 15,0 & 15,46 \\
Pelotas - RS & 25,5 & 27,8 & 15,6 & 18 \\
Santa Maria - RS & 26,1 & 28,78 & 16,5 & 18,56 \\
São Luiz Gonzaga - RS & 28,2 & 30,5 & 17,1 & 19,5 \\
Torres - RS & 25,1 & 27,67 & 17,7 & 19 \\
Uruguaiana - RS & 28,1 & 29,5 & 18,9 & 18,9 \\
Florianópolis - SC & 26,5 & 29,3 & 19,5 & 19,2 \\
Lages - SC & 24,0 & 23,93 & 13,4 & 14,04 \\
Castro - PR & 25,8 & 27,1 & 15,0 & 14,29 \\
Curitiba - PR & 24,7 & 25,9 & 15,3 & 15,5 \\
Irati - PR & 25,2 & 26,2 & 14,2 & 13,9 \\
\hline
\end{tabular}




\begin{tabular}{ccccc}
\hline Ivaí - PR & 25,8 & 27,65 & 15,3 & 14,61 \\
Londrina - PR & 29,7 & 30,36 & 18,0 & 18,35 \\
Maringá - PR & 29,6 & 29,77 & 19,3 & 19,83 \\
Paranaguá - PR & 28,0 & 28,98 & 20,4 & 20,7 \\
\hline
\end{tabular}

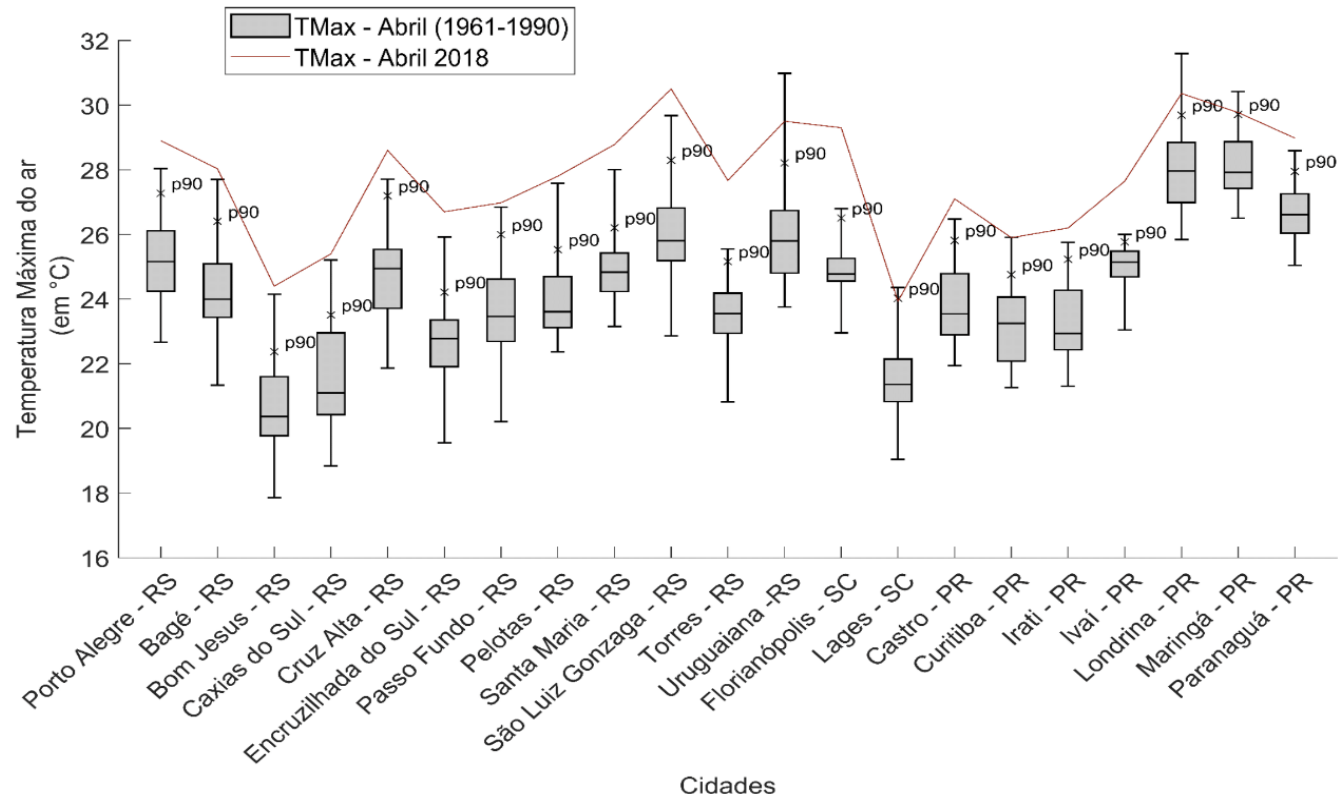

Figura 3 - Distribuição da temperatura máxima mensal de abril 1961-1990 (Boxplot cinza em ${ }^{\circ} \mathrm{C}$ ), para 21 estações da RSB. A linha cheia dentro da caixa representa 0 percentil $50 \%$ (mediana), o inferior da caixa representa o percentil $25 \%$, o superior da caixa $75 \%$ e o marcador (x) representa o percentil 90\% (p90). A linha cheia em vermelho escuro representa a temperatura máxima média mensal de abril-2018.

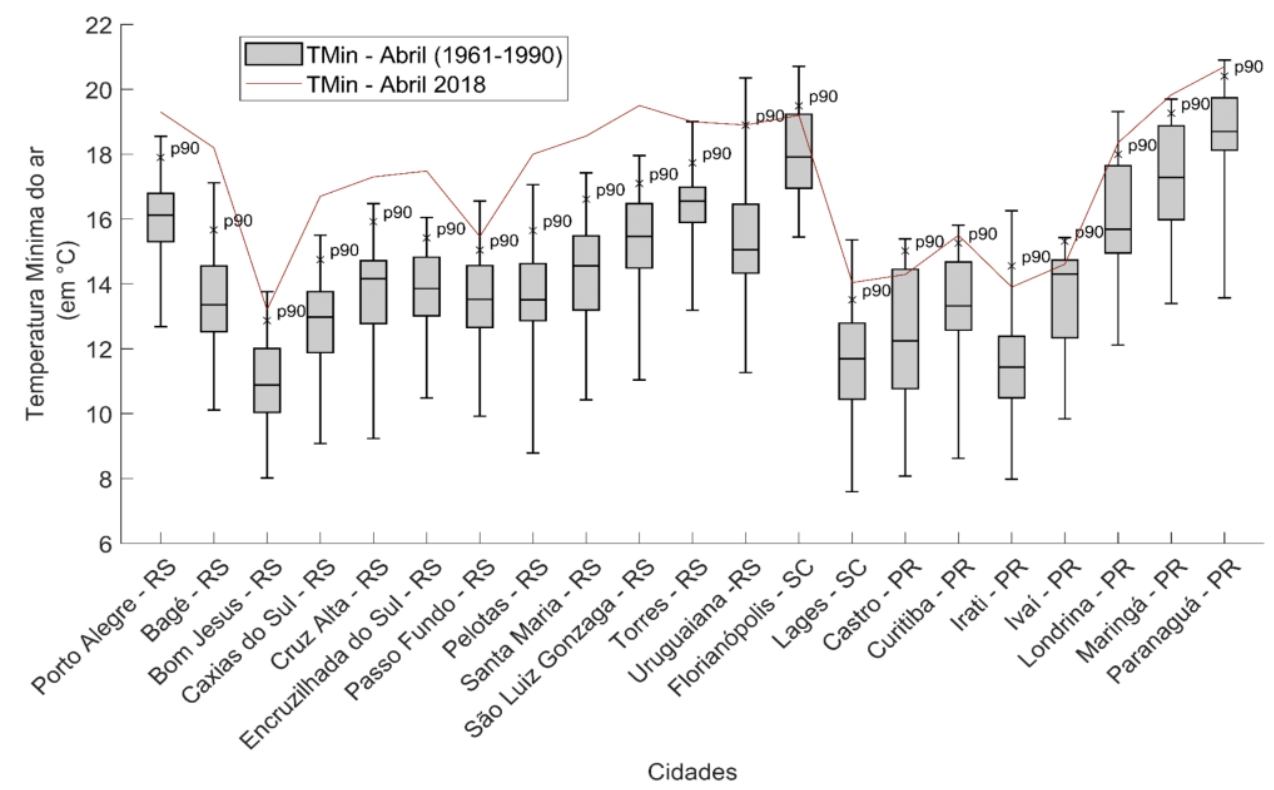

Figura 4 - Distribuição da temperatura mínima mensal de abril 1961-1990 (Boxplot cinza em ${ }^{\circ} \mathrm{C}$ ), para 21 estações da RSB. A linha cheia dentro da caixa representa o 
percentil $50 \%$ (mediana), o inferior da caixa representa o percentil $25 \%$, o superior da caixa $75 \%$ e o marcador (x) representa o percentil 90\% (p90). A linha cheia em vermelho escuro representa a temperatura mínima média mensal de abril-2018.

A Figura 5 apresenta os campos de temperatura média do ar a 2 metros da superfície (A) e umidade específica a 2 metros da superfície (B) para abril de 2018. Observa-se que temperaturas altas predominam sobre toda a RSB, com valores variando de $20^{\circ} \mathrm{C}$ na região oeste, e entre $18^{\circ} \mathrm{C}$ e $16^{\circ} \mathrm{C}$ nos setores leste e nordeste de cada estado, respectivamente. Para a região compreendida pelo Paraguai, sul da Bolívia e oeste de Mato Grosso do Sul, núcleos de temperatura com valores acima de $30^{\circ} \mathrm{C}$ são observados. Apenas ao sul da Argentina em torno de $40^{\circ} \mathrm{S}$ que percebe-se temperaturas relativamente mais frias $\left(14^{\circ} \mathrm{C}\right)$, porém que ainda assim representam valores elevados de temperatura ao se considerar temperaturas médias para essa faixa de latitude e época do ano. $O$ campo de umidade específica (Figura 5B) revela a presença signifcativa de vapor d'água disponível nos baixos níveis, o que é esperado, uma vez que a circulação do ASAS é dominante sobre a RSB e propícia um escoamento que transporta umidade do oceano adjacente para a região.
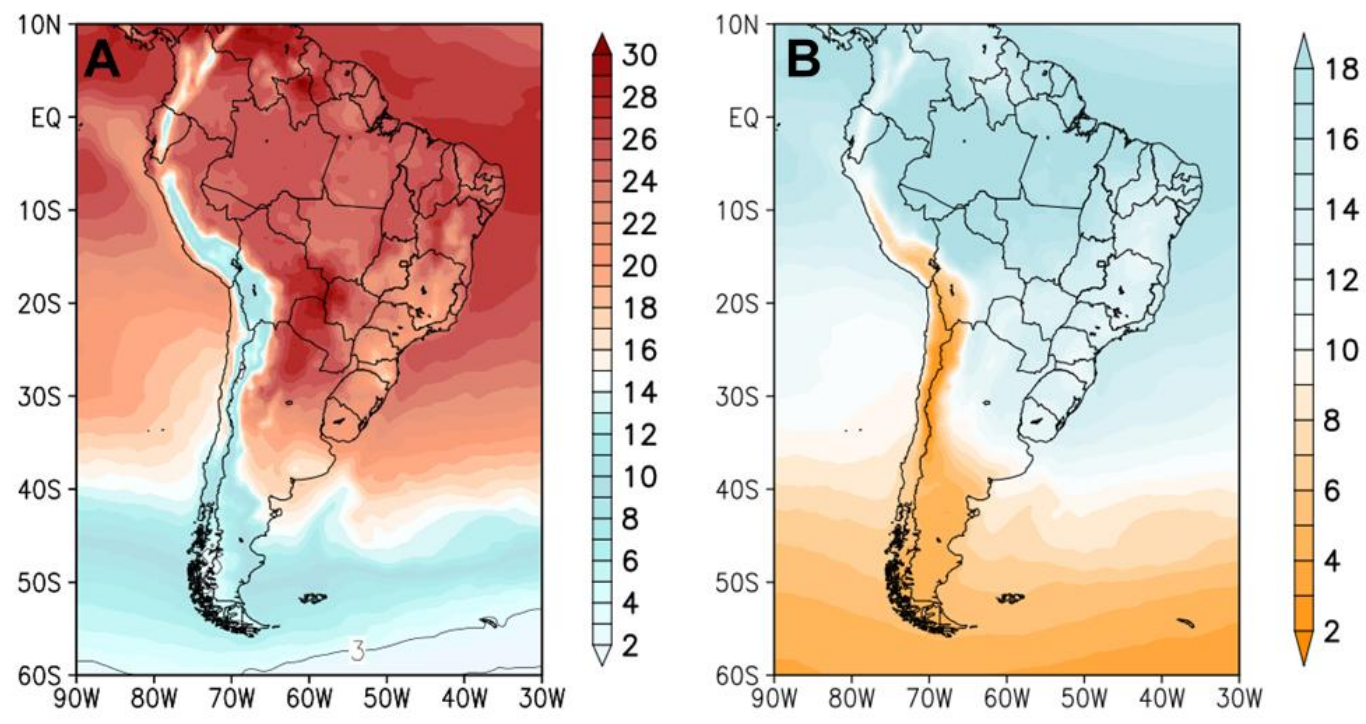

Figura 5 - Temperatura média mensal $\left(\mathrm{em}^{\circ} \mathrm{C}\right)$ a 2 metros da superfície $(A)$ e umidade específica (em g/Kg) a 2 metros da superfície (B) para abril de 2018.

A Figura 6 apresenta os campos de altura geopotencial e diferença (abril2018 - normal climatológica 1981-2010) de altura geopotencial em 500 hPa (Figura 6A), PNMM e diferença (abril2018 - normal climatológica 19812010) de PNMM (Figura 6B) para o mês de abril de 2018. Observa-se na Figura 6A a predominância de uma crista estacionária que se estende do Pacífico até o Oceano Atlântico adjacente $\left(35^{\circ} \mathrm{S} ; 20^{\circ} \mathrm{W}\right)$ posicionada no centro-sul do continente americano. Nota-se também a presença de um cavado (Figura 6A) a oeste do continente sul americano $\left(85^{\circ} \mathrm{W}\right)$ e de uma crista em $500 \mathrm{hPa}$ sobre o Pacífico em aproxidamente $120^{\circ} \mathrm{W}$. A diferença entre o campo de altura geopotencial de abril-2018 e sua respectiva série climatológica (1981-2010) apresenta valores positivos (circulação anticiclônica), notado sobre a região 
central da Argentina, sul do Paraguai, Uruguai, Rio Grande do Sul e adjacências, sugerindo um padrão de aquecimento da camada atmosférica durante o período estudado. Sabe-se que situações de bloqueio geralmente caracterizam-se pela permanência do regime de condições atmosféricas em uma determinada região. Esses regimes prolongados de condições atmosféricas sugerem a possibilidade de existência de anomalias de temperatura e/ou precipitação sobre a região abrangida pelo fenômeno sendo um dos possíveis fatores que levam a sua natureza persistente (SATYAMURTY et al., 1998; MARQUES, 1996; MENDES et al., 2005; JACONDINO et al., 2018). Ainda sobre o Pacífico junto à costa oeste da AS é possível notar valores de altura geopotencial abaixo da normal climatológica, presente ao longo do eixo do cavado descrito anteriormente, enquanto que a sudoeste $\left(50^{\circ} \mathrm{S} ; 120^{\circ} \mathrm{W}\right)$ um padrão oposto (valores acima da normal climatológica) de altura geopotencial é observado.

O campo de geopotencial em $500 \mathrm{hPa}$ (Figura 6A) indica a presença de uma crista sobre o centro-sul da AS, que fica estacionária por 15 dias ao longo do mês de estudo (aqui não apresentado), possivelmente associada a uma alta de bloqueio, enquanto que os valores de altura geopotencial que se apresentam acima da normal climatológica sobre a região reforçam o padrão de aquecimento da camada. Conforme descrito por Marques (1996); Satyamurty et al. (1998) e Mendes et al. (2005) esta estrutura caracteriza um padrão típico de bloqueio de crista estacionária de grande amplitude.

O campo de PNMM (Figura 6B) apresenta as isóbaras com uma orientação meridional de nordeste para sudoeste no flanco mais ocidental do ASAS e indica o predomínio de um escoamento anticiclônico sobre a RSB. O campo evidencia também duas regiões que apresentam PNMM com valores acima da normal climatológica: uma centrada sobre o Pacífico em $55^{\circ} \mathrm{S}$ e $120^{\circ} \mathrm{W}$ e outra sobre o oceano Atlântico em $45^{\circ} \mathrm{S}$ e $35^{\circ} \mathrm{W}$ com núcleo mais intenso situado a sudeste da costa do RS. Sabe-se que a RSB localiza-se entre duas regiões ciclogenéticas: a da costa do Uruguai e do extremo sul do Brasil e da costa sul/sudeste do Brasil (SINCLAIR, 1994; HOSKINS e HODGES, 2005; REBOITA, 2008). No entanto, nessa região para o período estudado nota-se a extensão de uma área com valores de PNMM acima da normal climatológica, atuando como agente inibidor na formação de ciclones, e, consequentemente, na propagação de frentes. Fato esse que pode ser comprovado ao se analisar os valores de PNMM abaixo da normal climatológica, que se encontram restritos ao sul da Argentina $\left(50^{\circ} \mathrm{S} ; 80^{\circ} \mathrm{W}\right)$, sugerindo que os sistemas transientes tais como frentes frias e os ciclones extratropicais se concentraram nesta região (Figura 7). Este aspecto está provavelmente associado a uma intensificação da migração para oeste do ASAS durante esse período, impondo uma alta pressão sobre toda a RSB. A presença de valores acima da normal climatológica no campo de altura geopotencial sobre a região enfraquecem os movimentos ascendentes e consequentemente a formação de nuvens, levando a um aumento da temperatura e desfavorecendo a passagem de frentes frias sobre 0 sul do Brasil. Diante deste cenário o ASAS tende a posicionar-se mais sobre o continente, impedindo assim a entrada de sistemas frontais que atuam tipicamente nessa época do ano na região sul. Devido a natureza persistente da configuração meteorológica descrita acima no mês de abril-2018, um padrão de bloqueio se estabeleceu sobre a região de estudo. 


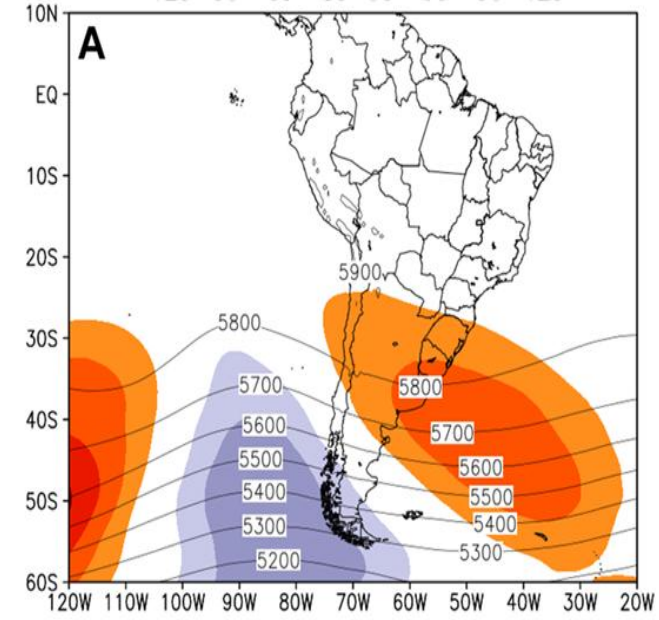

$-120-90-60-30 \quad 30 \quad 60 \quad 90 \quad 120$
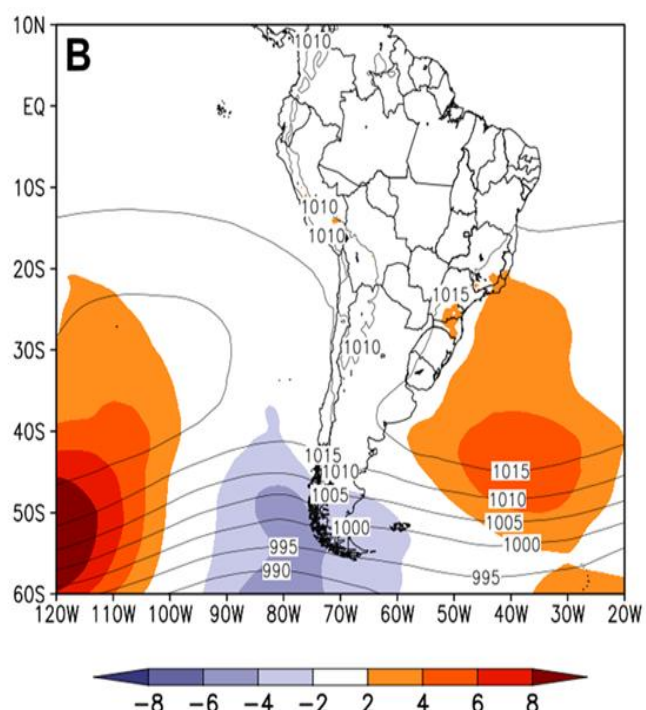

Figura 6 - Altura geopotencial (contorno em mgp) e diferença (abril2018 - normal climatológica 1981-2010) (sombreado) em $500 \mathrm{hPa}(\mathrm{A})$ e PNMM (contorno em hPa) e diferença (sombreado) (B) para abril de 2018.

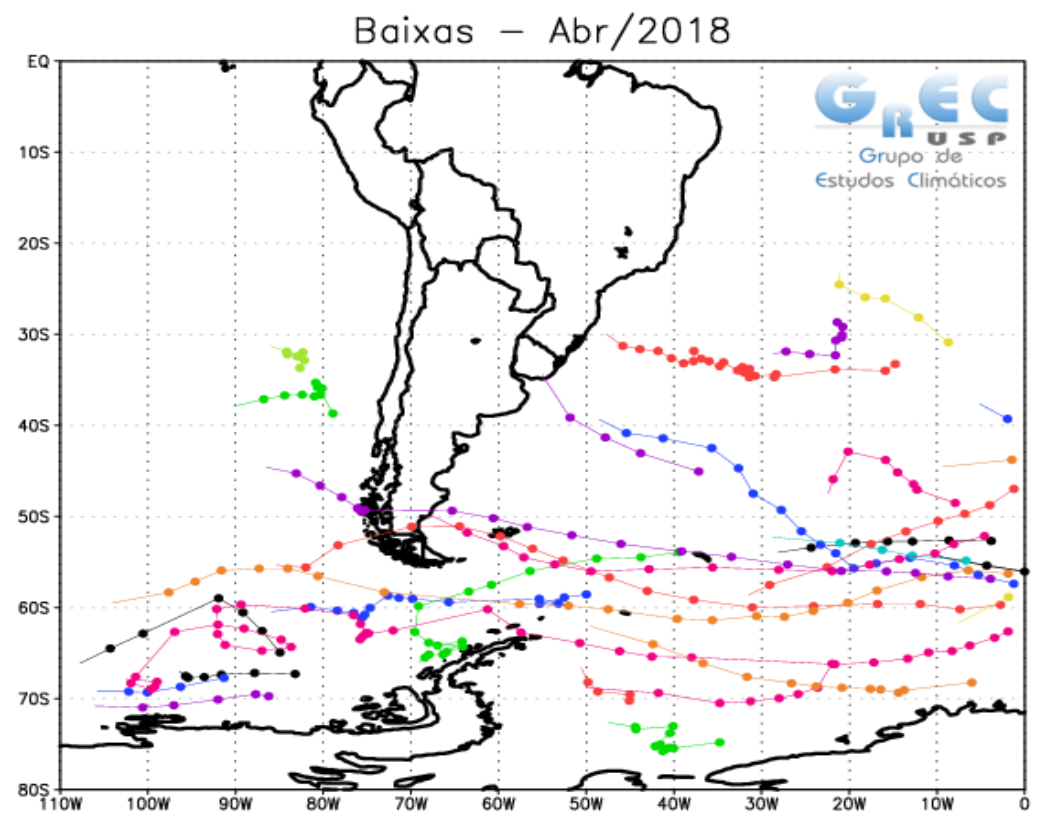

Figura 7 - Trajetória de ciclones no mês de abril de 2018. Fonte: GrEC - USP: http://www.grec.iag.usp.br/data/ciclones_BRA.php (2018).

A Figura 8 apresenta os campos de linha de corrente e magnitude do vento em $250 \mathrm{hPa}$ (Figura 8A) e linhas de corrente com umidade relativa em $850 \mathrm{hPa}$ (8B) para abril de 2018. O campo mostra a corrente de jato contornando a crista observada em níveis médios (Figura $8 \mathrm{~A}$ ), e deslocada mais ao sul, indicando uma menor frequência de instabilidades baroclínicas na região de estudo. Nos baixos níveis (Figura 8B), percebe-se um escoamento 
predominantemente de norte associado ao ASAS, auxiliando na manutenção de umidade sobre a RSB. Percebe-se também que esse escoamento apresenta-se ligeiramente mais intenso sobre o centro-norte da Argentina e o Paraguai, notado pelo aumento do gradiente das linhas de corrente.

Os campos em 850hPa (Figura 9A) tendem a apresentar o comportamento das massas de ar. Nota-se o domínio de uma massa de ar quente (Figura 9A) que apresenta-se mais intensa sobre o centro da Argentina, mas que também exerce influência sobre a RSB e adjacências. Isso pode ser comprovado ao se analisar a magnitude da diferença de temperatura do mês de abril-2018 com sua série climatológica, onde sobre o centro da Argentina temperaturas de $3^{\circ} \mathrm{C}$ acima da normal climatológica são observadas. Na RSB essas diferenças de temperatura apresentam valores intermediários variando entre $1,5^{\circ} \mathrm{C}$ no RS, e mínimos de $1^{\circ} \mathrm{C}$ acima da normal para os estados de SC e $\mathrm{PR}$, e evidenciam um decaimento de magnitude em direção ao norte. A presença de temperaturas elevadas do que a normal climatológica em $850 \mathrm{hPa}$ (Figura 9A) sugerem um sobreaquecimento nesta parte da camada atmosférica durante o mês de abril de 2018, que pode ser explicado pelo aquecimento adiabático provocado pelo movimento subsidente na região da crista de bloqueio (Figura 6A), refletindo no aumento significativo da temperatura em superfície (Figura 5A). Tal padrão pode ser associado à escassez de chuvas que predominou na maior parte das localidades da região de estudo (INMET, 2018b), uma vez que a chuva age como mecanismo termorregulador. Com pouca cobertura de nuvens, pouca chuva e maior incidência de radiação solar, as temperaturas médias mensais do mês de abril ficaram mais altas do que o normal.

O campo de umidade específica em $850 \mathrm{hPa}$ (Figura 9B) apresenta-se semelhante ao da Figura 8B, mostrando uma atmosfera com conteúdo significativo de umidade nos baixos níveis sobre todo o centro sul da AS até o paralelo de $34^{\circ} \mathrm{S}$. Esse conteúdo de umidade presente sobre a região contribui com os valores de temperatura observados (Figuras 5A e 9A), sugerindo que durante o período estudado as latitudes médias estiveram sob influência de uma massa de ar com características tropicais.
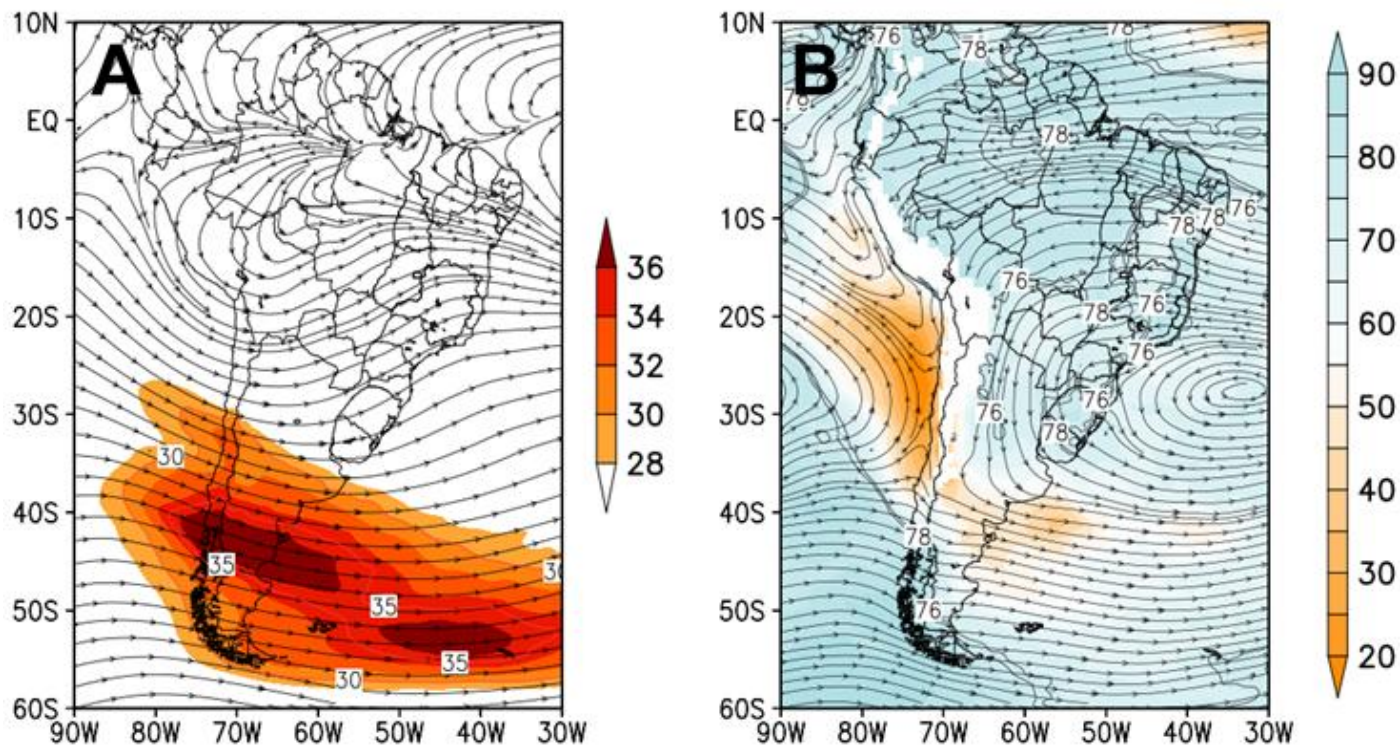
Figura 8 - Linhas de corrente e magnitude do vento (sombreado em m.s ${ }^{-1}$ ) em $250 \mathrm{hPa}$ (A) e linhas de corrente com umidade relativa (sombreado em \%) em $850 \mathrm{hPa}$ (B) para abril de 2018.
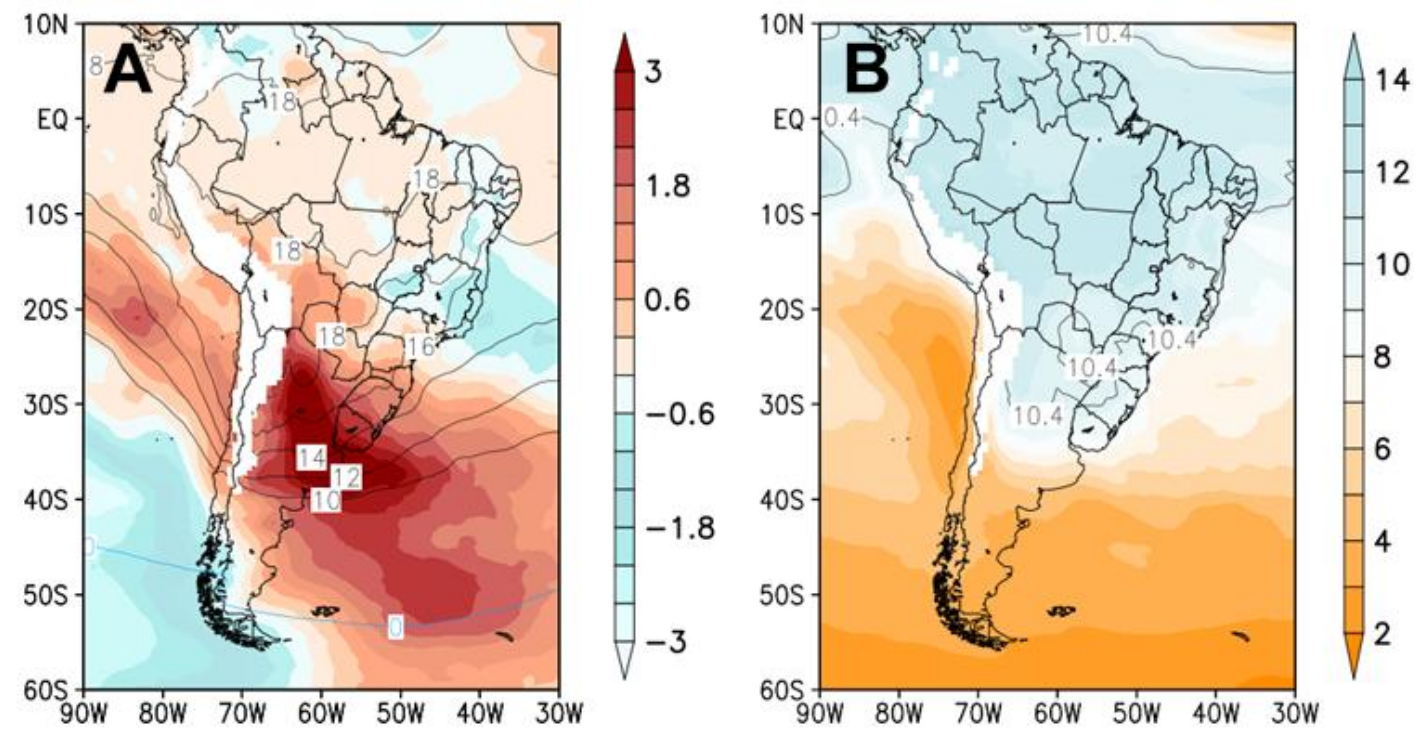

Figura 9 - Temperatura média mensal (contorno em ${ }^{\circ} \mathrm{C}$ ) e diferença (abril2018 - normal climatológica 1981-2010) (sombreado em ${ }^{\circ} \mathrm{C}$ ) em $850 \mathrm{hPa}(\mathrm{A})$ e umidade específica $(\mathrm{g} / \mathrm{Kg})$ em $850 \mathrm{hPa}(\mathrm{B})$ para abril de 2018.

A Figura 10 apresenta a diferença (abril-2018 - série climatológica) de umidade específica em $850 \mathrm{hPa}(\mathrm{A})$ e de linhas de corrente em $850 \mathrm{hPa}(\mathrm{B})$ para o mês em questão. Observa-se que condições de umidade específica com valores mais altos do que o normal predominam sobre o RS (Figura 10A), enquanto que em SC percebe-se mais um padrão de neutralidade (com exceções para o extremo oeste e sul do estado onde a magnitude desta diferença apresenta sinais de decaimento na intensidade). A configuração para o estado do PR é semelhante a de SC (com exceção dos valores negativos de umidade especifica que apresentam-se abaixo da normal climatológica localizado ao sul da região). Os desvios positivos mais expressivos de umidade especifica centrados no RS explicam o fato das temperaturas se apresentarem mais altas nesta região (Tabela 2 e Figura $5 \mathrm{~A}$ ), principalmente nas temperaturas minimas mais elevadas (Tabela 2). Isso ocorre porque o vapor d'água é um gás estufa e age como um mecanismo regulador da temperatura, portanto, um excesso desse gás implicaria em retenção de radiação de onda longa à noite nesta parte da camada atmosférica e acarretaria em temperaturas mínimias não tão baixas quanto o normal para esse período do ano. Na literatura estudos como o de Bezzera e Nunes (2017) apresentam resultados semelhantes em períodos de calor extremo no sul do Brasil. Para Paltridge et al. (2009) a tendência no comportamento anômalo positivo de umidade específica em 850 $\mathrm{hPa}$ pode ser explicada devido à tendência no sentido de diminuição do gradiente vertical de temperatura dentro da camada limite convectiva, indicando um aumento da temperatura. O comportamento do vento por meio do campo de linha de corrente (abril-2018 - série climatológica) no nível de 850 hPa (Figura 10B) para o mês de abril de 2018 mostra a presença de um anticiclone atípico bem mais ao sul do que a posição normal do ASAS para esta época do ano. Tal configuração dificultou a propagação dos sistemas frontais para o sul do Brasil, além de diminuir a presença de nebulosidade e favorecer a ocorrência de 
movimentos decendentes do ar sobre essa região. Diante disso, temperaturas elevadas permaneceram concentradas na baixa troposfera de modo a intensificar os desvios positivos de temperatura observada nesta parte da camada atmosférica ( $850 \mathrm{hPa}$ ) sobre a região de estudo durante o abril de 2018 (Figura 9A). Além disso, percebe-se também a presença de um cavado invertido (polígono em vermelho) de pequena amplitude sobre o litoral da RSB (Figura 10B) que pode estar associado aos desvios positivos de chuva observados no litoral gaúcho (INMET, 2018b).
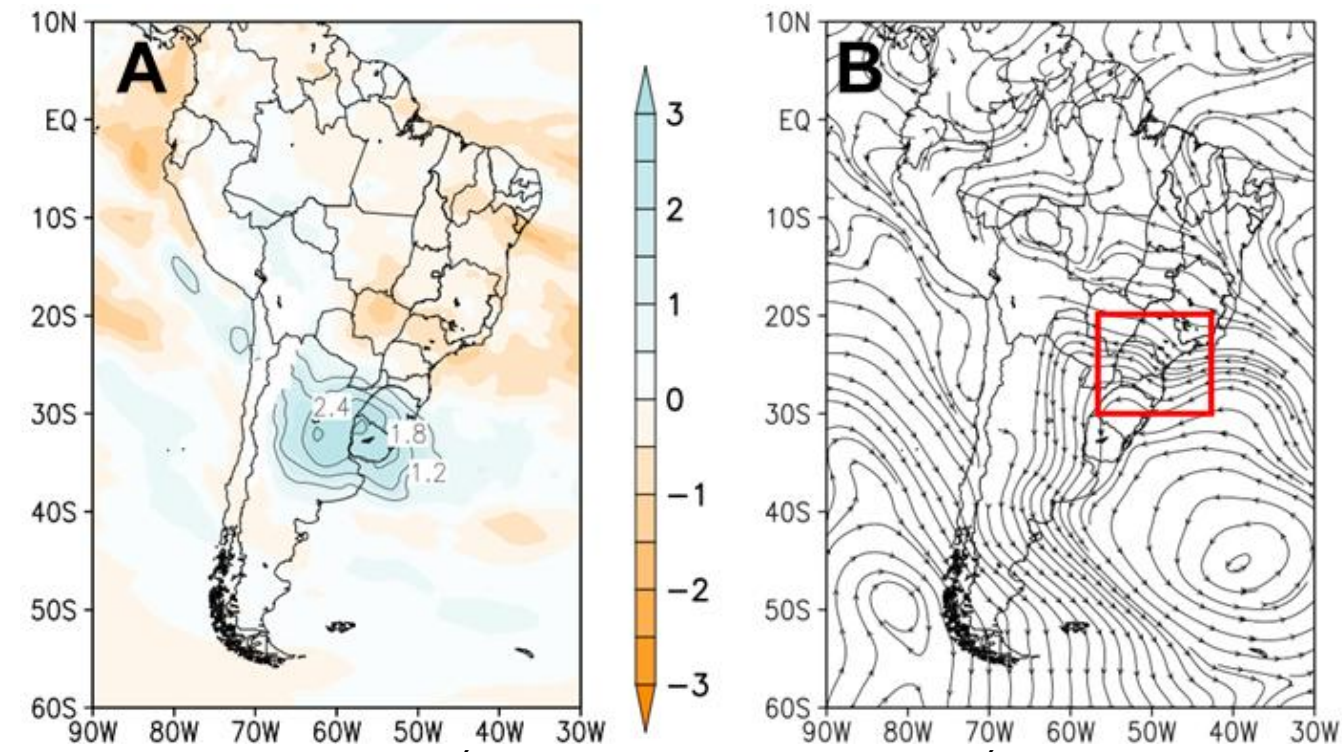

Figura 10 - umidade específica (abril2018 - normal climatológica 1981-2010) (em g/Kg, sombreado e com contorno destacando os desvios positivos) em $850 \mathrm{hPa}(\mathrm{A})$ e linhas de corrente (abril2018 - normal climatológica 1981-2010, o polígono em vermelho destaca a região de um cavado invertido) em 850 hPa (B) para abril de 2018.

A configuração do escoamento em 500 hPa para o abril de 2018 (Figura 11A) mostra um sistema fechado de circulação anticiclônica centrado em aproximadamente $20^{\circ} \mathrm{S}$ e $68^{\circ} \mathrm{W}$. Essa circulação é um reflexo da Alta da Bolívia (AB) (KOUSKY, 1981; SILVA DIAS et al., 1983; DEMARIA, 1985; FIGUEROA et al., 1995; REBOITA et al., 2010) que durante este mês esteve mais ao sul e oeste em relação a sua localização climatológica de abril com referência ao período 1981-2010 (Figura 11A). Desta forma, o Cavado do Nordeste Brasileiro que se forma corrente abaixo da Alta Bolívia devido à conservação da vorticidade absoluta (SATYAMURTY et al., 1998) também se apresentou mais ao sul, neste caso, sobre a região sudeste do Brasil. Essa configuração mais ao sul da $A B$ explica a presença dos desvios positivos de altura geopotencial (Figura $6 \mathrm{~A})$, sugerindo a existência de um escoamento canalizado das regiões tropicais para as latitudes médias, implicando em uma camada atmosférica mais quente (expandida) (Figura 12A). Isso pode ser melhor observado ao analisar o comportamento das linhas de corrente em 500 hPa (Figura 11C) que evidencia a presença de uma ampla circulação anticiclônica dominando o escoamento nos níveis médios sobre o sul da AS. Esta circulação sugere uma advecção quente (Figuras 12A e 12B) e consequentemente a expansão da camada, principalmente sobre o centro da Argentina onde as temperaturas mais elevadas estão concentradas (Figuras 9A). A configuração persistente de bloqueio somado 
ao escoamento constante de norte nos baixos níveis sobre a RSB favoreceu a ocorrência dos episódios de calor nas latitudes médias com extremos de temperatura registrados em toda RSB durante o abril de 2018, o que dificultou a propagação de sistemas frontais e ar frio para a região.
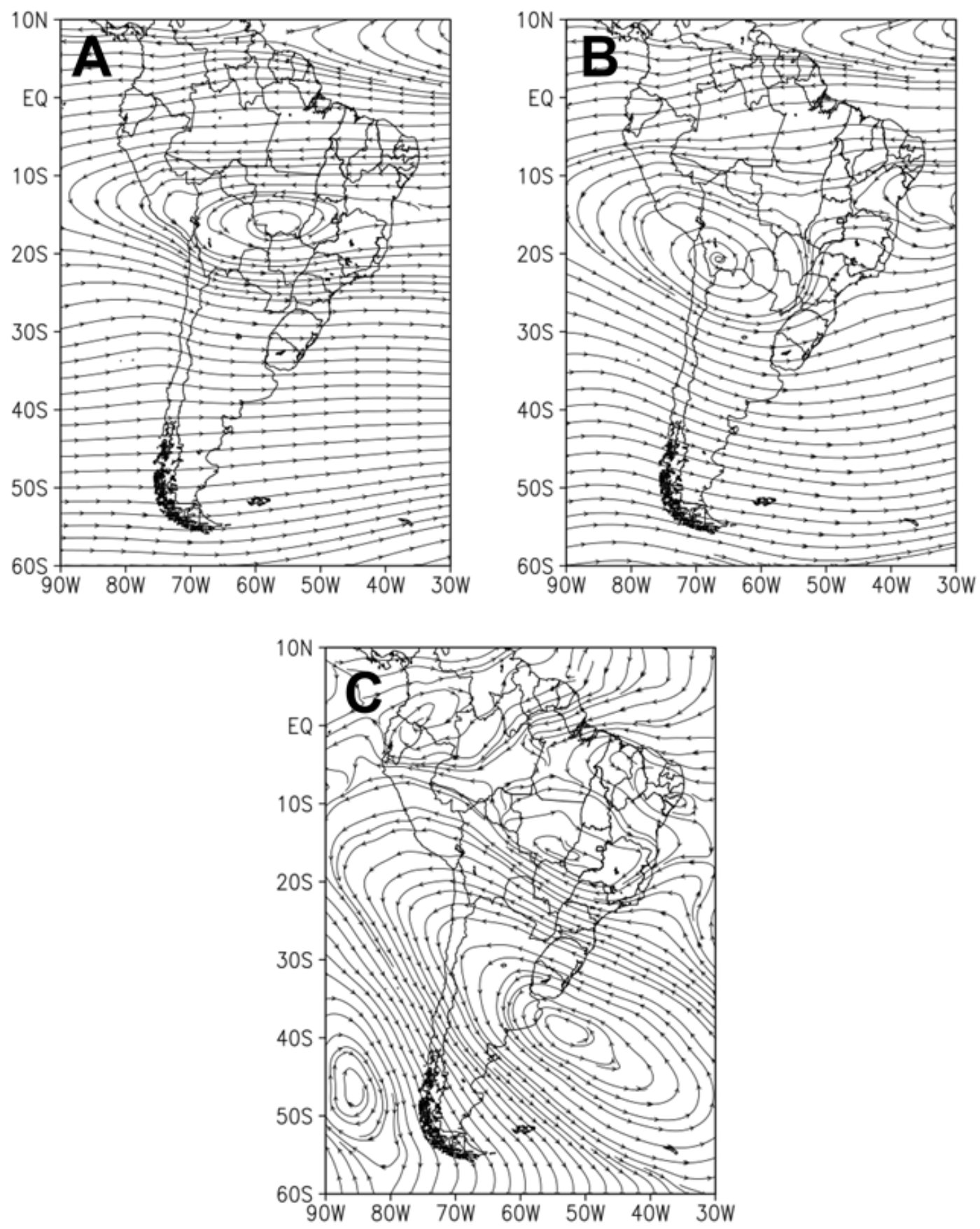
Figura 11 - Linha de corrente climatológica (1981-2010) para o mês de abril em 500 $\mathrm{hPa}$ (A), linha de corrente em $500 \mathrm{hPa}$ para o abril-2018 (B) e linha de corrente (abril2018 - normal climatológica 1981-2010) em 500 hPa (C).
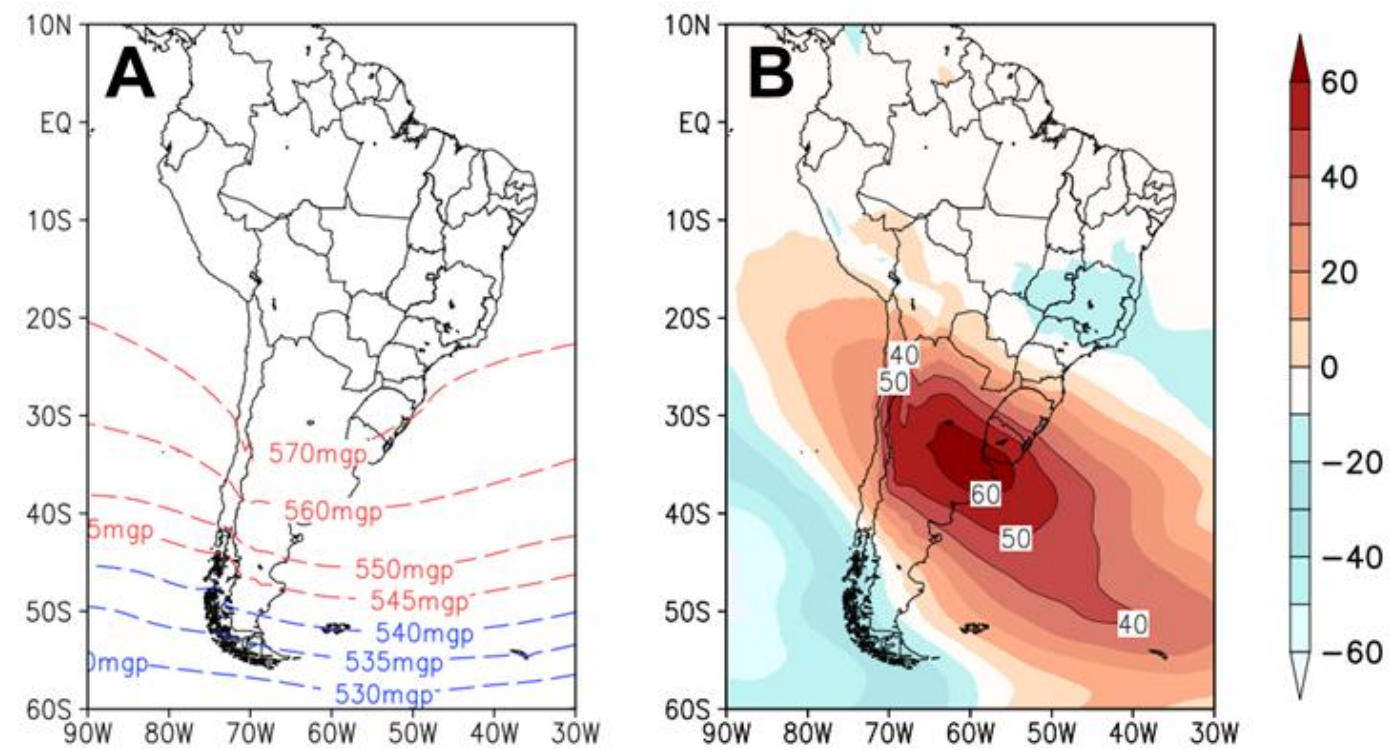

Figura 12 - Espessura entre 500 e 1000 hPa (em mgp) (A) e diferença de espessura (abril2018 - normal climatológica 1981-2010) entre 500 e 1000 hPa (em mgp) (B) para abril de 2018.

\section{CONCLUSÕES}

Este trabalho teve por objetivo verificar o ambiente atmosférico a partir de uma análise sinótica que propiciou as temperaturas máximas e mínimas notadamente mais elevadas do que a série histórica de referência na região Sul do Brasil durante o abril de 2018. O uso do p90 serviu como limiar para identificar os extremos de calor ocorridos na RSB durante o período de estudo, onde se constatou que as temperaturas máximas e mínimas apresentaram magnitude diferenciada entre as estações analisadas mas em geral mais elevadas do que o p90 da série histórica para essa época do ano.

As análises indicam que as temperaturas mais elevadas do que p90 observadas na RSB estiveram associadas com a presença simultânea de uma crista estacionária sobre o centro-sul da América do Sul em níveis médios e de um anticiclone atípico sobre o Oceano Atlântico em baixos níveis localizado bem mais ao sul que a posição normal do ASAS para esse mês do ano. Esta configuração caracterizou uma situação de bloqueio nos baixos níveis da atmosfera, impedindo que sistemas frontais avançassem sobre a região e advectassem ar frio, o que manteve as temperaturas elevadas no sul do Brasil.

O escoamento mais intenso dirigido para o centro da Argentina esclarece o fato dos desvios de temperatura em $850 \mathrm{hPa}$ serem maiores nesta região do 
que os desvios observados na RSB. As análises também mostraram que a presença do ASAS posicionado mais próximo do continente foi um fator importante para a ocorrência dos desvios positivos de umidade específica em baixos níveis que ajudaram na manutenção das altas temperaturas. Os desvios de umidade específica em baixos níveis ( $850 \mathrm{hPa}$ ) ajudaram a manter as temperaturas mínimas mais elevadas do que o p90 da série histórica em diversas localidades da RSB uma vez que o vapor d'água em excesso nesta parte da camada atmosférica reteve radiação de onda longa e dificultou a perda radiativa da superfície terrestre.

De maneira geral a análise dos campos de altura geopotencial, linhas de corrente, temperatura, espessura (500 - $1000 \mathrm{hPa}$ ) e umidade específica em diversos níveis mostraram uma configuração sinótica de um perfil atmosférico relativamente quente e seco nos níveis médios induzido pela presença de padrões de circulação anticiclônica conjugados com um escoamento úmido de norte nos níveis mais baixos direcionado para a RSB como um fator importante para os extremos de calor observados na região de estudo.

O presente estudo aqui apresentado e a metodologia utilizada tiveram como foco identificar episódios de extremo calor no sul do Brasil e estabelecer uma ligação entre esses eventos e os mecanismos de grande escala que são responsáveis por seu início. No Brasil existem muito poucos trabalhos que avaliem de forma objetiva as condições atmosféricas associadas a eventos como esses, que são frequentemente associados as mudanças climáticas. Sendo assim, a elaboração do presente trabalho visa contribuir com a literatura para aprimorar o entedimento do ambiente atmosférico associados a eventos extremos de calor e servir de alicerce para que trabalhos futuros explorando essa temática na América do Sul sejam realizados.

\section{AGRADECIMENTOS}

Os autores agradecem ao INMET (Instituto Nacional de Meteorologia) pela concessão dos dados e ao Conselho Nacional de Desenvolvimento Cientifíco e Tecnológico (CNPq) pela bolsa de mestrado concedida ao primeiro autor.

\section{REFERÊNCIAS BIBLIOGRÁFICAS}

ANDRADE, K. M. Climatologia e Comportamento dos Sistemas Frontais sobre a América do Sul. Dissertação de Mestrado em Meteorologia. Instituto Nacional de Pesquisas Espaciais, São José dos Campos, 2007.

BARNES, EA.; SLINGO, J.; WOOLLINGS, T. A methodology for the comparison of blocking climatologies across indices, models and climate scenarios. Climate Dynamics, v. 38, p. 2467-2481, 2012. DOI: 10.1007/s00382-011-1243-6.

BEZERRA, J. M. Configuração meteorológica do verão (2013-2014) anomalamente quente das regiões Sul e Sudeste do Brasil. Dissertação de Mestrado em Meteorologia. Universidade Federal de Pelotas, Pelotas, 2016.

BEZERRA, J. M.; NUNES, A. B. Anomalias de Circulação Atmosférica em Baixos Níveis do Verão (2013-2014) Anomalamente Quente nas Regiões Sul e Sudeste do Brasil. Anuário do Instituto de Geociências, v.40, p. 93-101, 2017. 
BITENCOURT, D.P.; FUENTES, M.V.; MAIA, P.A.; AMORIM, F.T. Frequência, Duração, Abrangência Espacial e Intensidadedas Ondas de Calor no Brasil. Revista Brasileira de Meteorologia, v. 31, n. 4, p. 506-517, 2016.

BLACK, E.; BLACKBURN, M.; GARRISON, G.; HOSKINS, B.; METHVEN, J. Factors contributing to the summer 2003 European heatwave. Weather, v. 59, n. 8, p. 217-223, 2004. DOI: doi.org/10.1256/wea.74.04.

BONATTI, J. P.; RAO, V. B. Moist baroclinic instability of North Pacific and South American intermediate-scale disturbances. Journal of the Atmospheric Sciences, v. 44, p. 2657-2667, 1987.

CAVAlCANTI, I, F. D. A. et al. Tempo e Clima no Brasil. 1 ed. São Paulo: Oficina de Textos, 2009a. 464 p.

CAVALCANTI, I. F. A.; KOUSKY, V. E. Frentes frias sobre o Brasil. In: Cavalcanti, I. F. A.; Ferreira, N. J.; Justi da Silva, M. G. A.; Silva Dias, M. A. F. (Eds.) Tempo e clima no Brasil. São Paulo, Oficina de Textos. 2009b. p.135-148.

CECCHERINI, G.; RUSSO, S.; AMEZTOY, I.; PATRICIA ROMERO, C. \& CARMONAMORENO, C. Magnitude and frequency of heat and cold waves in recent decades: The case of South America. Natural Hazards and Earth System Sciences, v. 16, n. 3, p. 821-831, 2016.

CERNE, S.B. \& VERA, C.S. Influence of the intraseasonal variability on heat waves in subtropical South America. Climate Dynamics, v. 36, n. 11-12, p. 2265-2277, 2011.

CPTEC/INPE. 2018. Centro de Previsão de Tempo e Estudos Climáticos/Instituto Nacional de Pesquisas Espaciais. Disponível em: www.cptec.inpe.br. Acesso em 2 de maio de 2018.

DEMARIA, M. Linear response of a stratified tropical atmosphere to convective forcing. Journal of the Atmospheric Sciences, v. 42, p. 1944-1959, 1985.

DOLE, R.; HOERLING, M.; PERLWITZ, J.; EISCHEID, J.; PEGION, P.; ZHANG, T.; QUAN, X-W.; XU. T.; MURRAY, D. Was there a basis for anticipating the 2010 Russian heat wave?. Geophysical Research Letters, v. 38, n. 6, L06702, 2011. DOI: https://doi.org/10.1029/2010GL046582.

FIGUEIREDO, J. C.; SCOLAR, J. O Tempo de Vida Médio dos Sistemas Convectivos de Mesoescala na América do Sul. In Congresso Brasileiro de Meteorologia, Campos de Jordão, SP, p. 984-986, 1996.

FIGUEROA; S. N., SATYAMURTY, P.; SILVA DIAS, P. L. Simulations of the summer circulation over the South American region with an eta coordinate model. Journal of the Atmpsheric Sciences, v. 52, p. 1573-1584, 1995.

FISCHER, E.M. \& SCHÄR, C. Consistent geographical patterns of changes in high-impact European heatwaves. Nature Geoscience, v. 3, n. 3, p. 398-403, 2010.

GEIRINHAS, J. L.; TRIGO, R.M.; LIBONATI, R.; PERES, L. DE FARIA. Climatic Characterization of Heat Waves in Brazil. Anuário do Instituto de Geociências, v. 41, n. 3, p.333-350, 2018. http://dx.doi.org/10.11137/2018_3_333_350.

GEIRINHAS, J.L.; TRIGO, R.M.; LIBONATI, R.; COELHO, C.A.S. \& PALMEIRA, A.C. 2017. Climatic and synoptic characterization of heat waves in Brazil. International Journal of Climatology, 38: 1760-1776. 
GELARO, R.; MCCARTY, W.; SUÁREZ, M.J.; TODLING, R.; MOLOD, A.; TAKACS, L.; RANDLES, C.A.; DARMENOV, A.; BOSILOVICH, M.G.; REICHLE, R.; WARGAN, K.; COY, L.; CULLATHER, R.; DRAPER, C.; AKELLA, S.; BUCHARD, V.; CONATY, A.; SILVA, A.M.; GU, W.; KIM, G-K.; KOSTER, R.; LUCCHESI, R.; MERKOVA, D.; NIELSEN, J.E.; PARTYKA, G.; PAWSON, S.; PUTMAN, W.; RIENECKER, M.; SCHUBERT, S.D.; SIENKIEWICZ, M.; ZHAO, B. The Modern-Era Retrospective Analysis for Research and Applications, Version 2 (MERRA-2). Journal of Climate, v. 30, p. 5419-5454, 2017.

HALLAK, R. Aspectos dinâmicos e simulação numérica da formação e evolução de um vórtice de ar frio. Dissertação de Mestrado em Meteorologia. Instituto Astronômico Geofísico e de Ciências Atmosféricas, São Paulo, 2000.

HANNART, A.; VERA, C.; OTTO, F.E.L. \& CERNE. B. Causal influence of anthropogenic forcings on the Argentinian heat wave of december 2013. Bulletin of the American Meteorological Society, v. 96, n. 12, p. S41-S45, 2015.

HOSKINS, B. J.; HODGES, K. I. A New on Southern Hemisphere Storm Tracks. Journal of Climate, v. 18, p. 4108-4129. 2005.

Instituto Nacional de Meteorologia - INMET 2018a. Banco de dados meteorológicos para ensino e pesquisa [online]. Disponível em: http://www.inmet.gov.br/projetos/rede/pesquisa/início.php. Acesso em: 25 de maio de 2018.

Instituto Nacional de Meteorologia - INMET 2018b. Desvio de Chuva Acumulada Total Mensal (mm) para o mês de abril de 2018. Disponível em: http://www.inmet.gov.br/portal/index.php?r=clima/desvioChuvaMensal. Acesso em: 6 de junho de 2018.

IWABE, C. M. N.; ROCHA, R. P. An event of stratospheric air intrusion and its associated secondary surface cyclogenesis over the South Atlantic Ocean. Journal of Geophysical Research, v. 114, D09101, 2009. DOI: 10.1029/2008JD011119.

JACONDINO, W. D.; CONRADO, H.; NASCIMENTO, A. 2018. Análise de Veranicos Intensos na Região Sul do Brasil e Condições Sinóticas Associadas. Anuário do Instituto de Geociências, 41: 337-389.

JUSTI DA SILVA, M. G. A.; SILVA DIAS, M. A. F. A frequência de fenômenos meteorológicos na América do Sul: uma climatologia. In Congresso Brasileiro de Meteorologia, Foz do Iguaçu, 2002. Anais... Foz do Iguaçu: SBMET, 2002. 1 CDROM.

KOUSKY, V. E. Frontal Influences on Northeast Brazil. Monthly Weather Review, v. 107, p. 1140-1153, 1979.

KOUSKY, V. E.; GAN, M. A. Upper tropospheric cyclonic vórtices in Tropical SouthAtlantic. Tellus, v. 33, p. 538-551. 1981.

LAU, NGAR-CHEUNG; NATH, MARY JO. A Model Study of Heat Waves over North America: Meteorological Aspects and Projections for the Twenty-First Century. Journal Of Climate, v. 25, n. 14, p.4761-4784, 2012.

LEE, YUN-YOUNG; GROTJAHN, RICHARD. CALIFORNIA CENTRAL VALLEY SUMMER Heat Waves Form Two Ways*. Journal Of Climate, v. 29, n. 3, p.12011217, fev. 2016. http://dx.doi.org/10.1175/jcli-d-15-0270.1. 
LEMOS, C. F.; CALBETE, N. O. Sistemas frontais que atuaram no litoral de 19871995. Climanálise, Edição comemorativa 10 anos, 1996. (INPE-10717PRE/6178).

MARENGO, J. A.; CAMARGO, C. C. Surface air temperature trends in Southern Brazil for 1960-2002. International Journal of Climatology, v. 28, n. 7, p. 893904, 2008.

MARQUES, R F. C. Bloqueio Atmosférico no Hemisfério Sul. 1996. Tese (Doutorado em Meteorologia). Instituto Nacional de Pesquisas Espaciais, São José dos Campos, 1996.

MARQUES, R. F. C.; RAO V. B. A diagnosis of long-lasting blocking event over the Southeast Pacific Ocean. Monthly Weather Review, v. 127, p. 1761-1776, 1999.

MEEHL, G. A.; TEBALDI, C. More intense, more frequent, and longer lasting heat waves in the 21st century. Science, v. 305, n. 5686, p. 994-997, 2004.

MENDES, M.C.D; TRIGO, R.M; CAVALCANTI, I.F.A \& DACAMARA, C.C. Bloqueios atmosféricos de 1960 a 2000 sobre o oceano pacífico sul: Impactos climáticos e mecanismos físicos associados. Revista Brasileira de Meteorologia, v. 20, p. 175-190, 2005.

MIKY FUNATSU, B., GAN, M. A.; CAETANO, E. A case study of orographic cyclogenesis over South America. Atmósfera, v. 17, n. 2, p. 91-113, 2004.

MOTA, M. A. S.; NOBRE, C. A. Relação da variabilidade da energia potencial convectiva disponível (CAPE) com a precipitação e a alta da Bolívia durante a campanha Wet-AMC/LBA. Revista Brasileira de Meteorologia, Brasil, v. 21, n. 3b, p. 344-355, 2006.

NASCIMENTO, E. L.; AMBRIZZI, T. The Influence of Atmospheric Blocking on the Rossby Wave Propagation in Southern Hemisphere Winter Flows. Journal of the Meteorological Society of Japan, v. 80, n. 2, p. 139-159. 2002.

National Oceanic and Atmospheric Administration (NOAA). April 2018 Was 3rd warmest on record for globe. Disponível em: http://www.noaa.gov/news/april2018-was-3rd-warmest-on-record-for-globe. Acesso em: 4 de junho de 2018.

OLIVEIRA, A. S. Interações entre sistemas frontais na América do Sul e convecção na Amazônia. INPE-4008-TDL/239, Dissertação de Mestrado em Meteorologia, Instituto Nacional de Pesquisas Espaciais, São José dos Campos, 1986.

PALTRIDGE, G.; ARKING, A.; POOK, M.; Trends in middle - and upper-level tropospheric humidity from NCEP reanalysis data. Theorical and Applied Climatology, v. 98, p. 351-359, 2009.

PERKINS, S.E \& Alexander, L.V. On the Measurement of Heat Waves. Journal of Climate, v. 26, n. 13, p. 4500-4517, 2013.

PFAHL, S.; SCHWIERZ, C.; CROCI-MASPOLI, M.; GRAMS, CM.; WERNLI, H. Importance of latent heat release in ascending air streams for atmospheric blocking. Nature Geoscience, v. 8, p. 610-614, 2015. DOI: 10.1038/ngeo2487.

REBOITA, M. S. Ciclones Extratropicais sobre o Atlântico Sul: Simulação Climática e Experimentos de Sensibilidade. 359f. 2008. Tese (Doutorado em 
Meteorologia) Instituto Astronômico Geofísico e de Ciências Atmosféricas, São Paulo, 2008.

REBOITA, M. S., GAN, M. A., ROCHA, R. P., AMBRIZZI, T. Regimes de precipitação na América do Sul: Uma revisão bibliográfica. Revista Brasileira de Meteorologia, v. 25, p. 185-204, 2010.

REBOITA, M. S.; AMBRIZZI, T.; ROCHA, R. P. Relationship between the Southern Annular Mode and Southern Hemisphere Atmospheric Systems. Revista Brasileira de Meteorologia, v. 24, n. 1, p. 48-55, 2009.

RENOM, M.; RUSTICUCCI, M. \& BARREIRO, M. Multidecadal changes in the relationship between extreme temperature events in Uruguay and the general atmospheric circulation. Climate Dynamics, v. 37, n. 11-12, p. 2471-2480, 2011.

RODRIGUES, M. L. G.; FRANCO, D.; SUGAHARA, S. Climatologia de Frentes Frias no Litoral de Santa Catarina. Revista Brasileira de Geofísica, v.22, n. 2, p. 135-151, 2004.

RUSTICUCCI, M. M.; VARGAS, W. M. Interannual variability of temperature spells over Argentina. Atmósfera, v. 14, p. 75-86, 2001.

RUSTICUCCI, M.; BARRUCAND, M. \& COLLAZO, S. Temperature extremes in the Argentina central region and their monthly relationship with the mean circulation and ENSO phases. International Journal of Climatology, v. 37, n. 6, p. 30033017, 2017.

RUSTICUCCI, M.; KYSELÝ, J.; ALMEIRA, G. \& LHOTKA, O. Long-term variability of heat waves in Argentina and recurrence probability of the severe 2008 heat wave in Buenos Aires. Theoretical and Applied Climatology, v. 124, n. 3-4, p. 679-689, 2016.

SALIO, P., NICOLINI, M.; ZIPSER, J. Mesoscale convective systems over southeastern South American low-level jet. Monthly Weather Review, v. 135, p. 1290-1309, 2007.

SATYAMURTY, P.; MATTOS, L. F. Climatological lower tropospheric frontogenesis in the midlatitudes due to horizontal deformation and divergence. Monthly Weather Review, v. 117, n. 6, p. 1355-1364, 1989.

SATYAMURTY, P.; NOBRE, C.A.; SILVA DIAS, P.L. Meteorology of the tropics: South America. In: KAROLY, D.J. \& VINCENT, D.G (eds.). Meteorology of Southern Hemisphere. Meteorological Monographs, 27(49): chapter 3A. 1998.

SILVA DIAS, P. L.; SCHUBERT, W. H.; DEMARIA, M. Large-scale response of the tropical atmosphere to transient convection. Journal of the Atmospheric Sciences, v. 40, p. 2689-2707, 1983.

SINCLAIR, M. R. Na Objective Cyclone Climatology for the Southern Hemisphere. Monthly Weather Review, v. 122, p. 2239-2256, 1994.

SOUZA, E. B. GrADS - Grid Analysis and Display System Fundamentos e rogramação Básica. Universidade Federal do Pará. 2004. Disponível http://www.dca.iag.usp.br/www/material/ritaynoue/aca0522/referencias/apostil agrads.pdf. Acesso em 30 de jul. de 2018.

XOPLAKI, E.; GONZÁLES-ROUCO, J. F.; LUTERBACHER, J.; WANNER, H. Mediterranean summer air temperature variability and its connection to the 
large-scale atmospheric circulation and SSTs. Climate Dynamics, v. 18, n. 23, p. 5011-5023, 2003. DOI: https://doi.org/10.1175/JCLI3589.1. 